\title{
FAKTOR DETERMINAN KEJADIAN MALARIA DI KECAMATAN TOHO KABUPATEN PONTIANAK
}

\author{
Anida Sari ${ }^{1)}$ Cecep Dani Sucipto $^{2)}$ Hajimi $^{3)}$ \\ ${ }^{1}$ Puskesmas Wajok Kabupaten Pontianak, ${ }^{2,3}$ Poltekkes Pontianak, Jurusan \\ Kesehatan Lingkungan, J1.28 Oktober Siantan Hulu Kota Pontianak
}

\begin{abstract}
Abstrak
Kabupaten Pontianak merupakan salah satu kabupaten di Kalimantan Barat yang endemis penyakit malaria. Berdasarkan laporan puskesmas pada tahun 2009 penemuan malaria klinis sejumlah 3138 kasus, mengalami peningkatan bila dibandingkan tahun 2008 sebesar 2432 kasus. Tujuan penelitian untuk mengetahui hubungan antara kebiasaan keluar malam, pemakaian kelambu, penggunaan obat anti nyamuk, kondisi dinding rumah, pemakaian kawat kasa, adanya hewan ternak dan genangan air disekitar rumah dengan kejadian malaria,serta menghitung besarnya risiko terjadinya malaria. Metode penelitian observasional analitik dengan rancangan studi kasus kontrol.Kasus adalah penduduk yang menderita penyakit malaria periode Januari sampai dengan Oktober 2011 dan kontrol adalah penduduk yang tidak menderita malaria.Jumlah responden sebanyak 94 sampel.Uji statistik yang digunakan yaitu analisis bivariat dengan uji chi square, untuk menghitung besar risiko dengan menggunakan Odds Ratio (OR). Hasil menunjukan bahwa faktor-faktor yang terbukti faktor resiko dengan kejadian malaria adalah: kebiasaan keluar malam, kondisi diding rumah, pemakaian kawat kasa, keberadaan hewan ternak, adanya genagan air disekitar rumah dan satu faktor pencegah yaitu penggunaan kelambu
\end{abstract}

Kata kunci: Faktor Determinan, Breeding pleaces, Kejadian Malaria, Entikong, Kalbar.

\section{ABSTRACT}

Pontianak regency was one of regencies in West Kalimantan endemic malaria. Based health centers in 2009 reported the discovery of a number of clinical malaria 
cases 3138 , an increase when compared to 2008 amounting to 2432 cases. The purpose of the study to determine the relationship between the habits of a night out, the use of mosquito nets, mosquito repellent use, condition of the walls of the house, the use of wire netting, introduction of livestock and puddles around the house with the incidence of malaria, as well as quantify the risk of malaria. Methods of observational analytic study design is a case study kontrol.Kasus residents who suffer from malaria from January until October 2011 and controls were residents who did not suffer as much as 94 malaria.Jumlah respondents used statistical sampel.Uji ie bivariate analyzes with chi square test, to calculate the risk of using the Odds Ratio ( $O R$ ). The results showed that the factors that proved to be risk factors with the incidence of malaria is : the habit of a night out, house Diding conditions, the use of wire netting, the presence of farm animals, the presence of water genagan around the house and the deterrent factor was the use of mosquito nets

Keywords : Determinant factors, Breeding pleaces, Genesis Malaria , Entikong, West Kalimantan

\section{Pendahuluan}

Selama tiga tahun terakhir dari tahun 2008 sampai 2010 indikator API mengalami peningkatan mencapai 2,4 \%o pada tahun 2010. Oleh karenanya status endemisitas malaria di Kabupaten Pontianak pada tahun 2010 merupakan daerah dengan Moderate Incidence Case (API <1\%o) (Dinkes Kab. Pontianak, 2010).

Kecamatan Toho sebagian besar merupakan kawasan hutan dan daerah rawa yang merupakan kawasan yang potensial untuk perkembangbiakan nyamuk Anopheles sp. Sedangkan secara sebagian pendudduk yang berdomisili di sekitar hutan beraktivitas menoreh getah karet pada saat waktu aktivitas menggigit nyamuk Anopheles sp yaitu pada jam 04.00-06.00, upaya mengurangi gigitan nyamuk pada sebagian penduduk masih belum optimal. Kondisi rumah penduduk yang masih banyak menggunakan dinding papan memungkinkan adanya celahcelah yang memungkinkan nyamuk bebas keluar masuk rumah.

Tujuan penelitian ini adalah mengetahui hubungan antara kebiasaan keluar malam, pemakaian kelambu, penggunaan obat anti nyamuk, kondisi dinding rumah, pemakaian kawat kasa, adanya hewan ternak dan genangan air disekitar rumah dengan kejadian 
malaria,serta menghitung besarnya risiko terjadinya malaria

\section{Metode Penelitian}

Jenis penelitian adalah obsevasional dengan metode survey menggunakan pendekatan kasus kontrol (case control). Populasi dalam penelitian ini adalah penduduk yang datang ke pelayanan kesehatan dan melakukan pemeriksaan darah malaria secara mikroskopis di Puskesmas Toho tahun 2011.

Sampel Kasus adalah Penderita yang didiagnosis malaria dengan ditemukan adanya plasmodium pada sediaan darah dari pemeriksaan mikroskopis di Puskesmas Toho periode bulan Januari s/d Nopember 2011,. Sedangkan Sampel kontrol adalah penderita yang tidak didiagnosis malaria dengan tidak ditemukan adanya plasmodium pada sediaan darah.

\section{Hasil}

Tabel 1 menunjukkan bahwa sebagian besar responden di Kecamatan Toho Kabupaten Pontianak tahun 2011 proporsi responden yang memiliki kebiasaan keluar malam dengan persentase $51,1 \%$, proporsi responden yang tidak menggunakan kelambu
$48,9 \%$, proporsi responden yang tidak menggunakan obat anti nyamuk yaitu sebesar $22,3 \%$, proporsi responden yang memiliki dinding rumah yang berisiko yaitu sebesar 54,3\%, proporsi responden yang tidak memasang kawat kasa pada ventilasi yaitu sebesar $80,9 \%$, proporsi responden yang memiliki hewan ternak yaitu sebesar $47,9 \%$, dan proporsi responden yang ada genangan air disekitar rumah yaitu sebesar 74,5 $\%$.

\section{Tabel 1. Distribusi frekuensi responden berdasarkan masing-masing variabel}

\begin{tabular}{lcc}
\hline \multicolumn{1}{c}{ Faktor Risiko } & Jumlah & \% \\
\hline Kebiasaan keluar malam: & 48 & 51,1 \\
Yang keluar rumah & 46 & 48,9 \\
Tidak pernah & & \\
Pemakaian kelambu & 46 & 48,9 \\
1. Tidak menggunakan & 48 & 51,1 \\
2. Menggunakan & & \\
Penggunaanobatantinyamuk & 21 & 22,3 \\
1. Tidak menggunakan & 73 & 77,7 \\
2. Menggunakan & & \\
Kondisi dinding rumah: & 51 & 54,3 \\
1. Berisiko & 43 & 45,7 \\
2. Tidak berisiko & & \\
Kawat kasa pada ventilasi: & 76 & 80,9 \\
1. Berisiko & 18 & 19,1 \\
2. Tidak berisiko & & \\
Keberadaan hewanternak: & 45 & 47,9 \\
1. Ada & 49 & 52,1 \\
2. Tidak ada & & \\
Genangan air sekitar rumah: & 70 & 74,5 \\
1. Ada & 24 & 25,5 \\
2. Memenuhi syarat & \multicolumn{2}{l}{} \\
\hline
\end{tabular}

Tabel 2 menunjukkan kecenderungan perilaku responden yang 
keluar malam pada kasus lebih tinggi dari pada kontrol yaitu sebesar $63,8 \%$.

Hasil uji chi-square, hubungan antara prilaku keluar rumah pada malam hari dengan kejadian malaria didapat nilai $\mathrm{p}=0,023$, dengan demikian $p$ value lebih kecil dari alpha (5\%) hingga $\mathrm{Ha}$ diterima, maka secara statistik dapat dikatakan ada hubungan yang bermakna antara prilaku keluar malam dengan kejadian malaria di wilayah Kecamatan Toho. Hasil perhitungan Odds Ratio (OR) diperoleh nilai 2,843 dengan 95\% Cofidence Interval $(\mathrm{CI})=1,232-6,563$; maka responden yang mempunyai kebiasaan keluar rumah pada malam hari mempunyai risiko 2,843 kali tertular penyakit malaria dibanding dengan responden yang tidak pernah keluar malam.

Tabel 2 menunjukkan kecenderungan responden yang tidak menggunakan kelambu pada kasus lebih besar dari pada kontrol yaitu sebesar $63,8 \%$.

Hasil uji chi-square, hubungan antara penggunaan kelambu dengan kejadian malaria didapat nilai $\mathrm{p}=0,007$, dengan demikian $p$ value lebih kecil dari alpha (5\%) sehingga Ha diterima, maka secara statistik dapat dikatakan ada hubungan yang bermakna antara penggunaan kelambu dengan kejadian malaria di wilayah Kecamatan Toho. Hasil perhitungan Odds Ratio (OR) diperoleh nilai 3,419 dengan 95\% Confidence Interval $(\mathrm{CI})=1,465-7,978$; maka responden yang tidak menggunakan kelambu mempunyai rersiko 3,419 kali tertular penyakit malaria dibanding responden yang menggunakan kelambu.

Tabel 2 menunjukkan kecenderungan responden yang tidak menggunakan obat anti nyamuk pada kasus lebih kecil dari pada kontrol yaitu sebesar $21,3 \%$. 
Tabel 2. Hasil analisis bivariat faktor rsiko yang berhubungan dengan kejadian Malaria di kecamatan Toho (September 2010 - Agustus 2011)

\begin{tabular}{lccccc}
\hline \multicolumn{1}{c}{ Variabel } & Kasus & Kontrol & OR & 95\% CI & p value \\
\hline $\begin{array}{l}\text { Kebiasaan keluar malam: } \\
\text { Ya }\end{array}$ & $63,8 \%$ & $38,3 \%$ & 2,843 & $1,232-6,563$ & 0,023 \\
$\begin{array}{l}\text { Tidak } \\
\text { Penggunaan kelambu }\end{array}$ & $36,2 \%$ & $61,7 \%$ & & & \\
$\begin{array}{l}\text { Tidak menggunakan } \\
\text { Menggunakan }\end{array}$ & $63,8 \%$ & $34,0 \%$ & 3,419 & $1,465-7,978$ & 0,007 \\
$\begin{array}{l}\text { Pemakaian obat anti nyamuk } \\
\text { Tidak menggunakan }\end{array}$ & $36,2 \%$ & $66,0 \%$ & & & \\
$\begin{array}{l}\text { Menggunakan } \\
\text { Kondisi dinding rumah: }\end{array}$ & $21,3 \%$ & $23,4 \%$ & 0,885 & $0,335-2,337$ & 1,000 \\
$\begin{array}{l}\text { Berisiko } \\
\text { Tidak berisiko }\end{array}$ & $78,7 \%$ & $76,6 \%$ & & & \\
$\begin{array}{l}\text { Pemakaian kawat kasa pada ventilasi: } \\
\text { Berisiko }\end{array}$ & $76,6 \%$ & $31,9 \%$ & 6,982 & $2,804-17,383$ & 0,000 \\
$\begin{array}{l}\text { Tidak berisiko } \\
\text { Keberadaan hewan ternak }\end{array}$ & $23,4 \%$ & $86,1 \%$ & & & \\
$\begin{array}{l}\text { Ada } \\
\text { Tidak ada }\end{array}$ & $93,6 \%$ & $68,1 \%$ & & & \\
Genangan air disekitar rumah: & $63,8 \%$ & $31,9 \%$ & 6,875 & $1,835-25,751$ & 0,004 \\
$\begin{array}{l}\text { Tidak memenuhi syarat } \\
\text { Memenuhi syarat }\end{array}$ & $36,2 \%$ & $68,1 \%$ & & & \\
\hline
\end{tabular}

Uji chi-square, hubungan antara penggunaan Obat anti nyamuk dengan kejadian malaria didapat nilai $\mathrm{p}=1,000$ dengan demikian $p$ value lebih besar dari alpha (5\%) sehingga Ha ditolak, maka secara statistik dapat dikatakan tidak ada hubungan yang bermakna antara penggunaan Obat anti nyamuk dengan kejadian malaria di wilayah Kecamatan Toho. Hasil perhitungan Odds Ratio (OR) diperoleh nilai 0,885 dengan $95 \%$ Confidence Interval $(\mathrm{CI})=0,335-2,337$; maka responden yang tidak menggunakan obat anti nyamuk mempunyai risiko 0,885 kali tertular penyakit malaria dibanding dengan responden yang tidak menggunakan obat anti nyamuk.
Tabel 2menunjukkan kecenderungan respoden yang kondisi dinding rumahnya berisiko pada kasus lebih besar dari pada kontrol yaitu sebesar 76,6\%.

Hasil uji chi square, hubungan antara kondisi dinding rumah yang berisiko dengan kejadian malaria didapat nilai $\mathrm{p}=0,000$, dengan demikian $p$ value lebih kecil dari alpha (5\%) sehingga Ha diterima, maka secara statistik dapat dikatakan ada hubungan yang bermakna antara kondisi dinding rumah dengan kejadian malaria di wilayah Kecamatan Toho. Hasil perhitungan Odds Ratio (OR) diperoleh nilai 6,982 dengan 95\% confidence Interval $(\mathrm{CI})=2,804-17,383$, maka responden yang kondisi diding rumahnya berisiko, 
mempunyai risiko 6,982 kali tertular penyakit malaria dibanding dengan responden yang kondisi dinding rumahnya tidak berisiko.

Tabel 2 menunjukkan kecenderungan respoden yang ventilasi rumahnya tidak dipasang kawat kasa nyamuk pada kasus lebih tinggi dari pada kontrol yaitu sebesar $93,6 \%$.

Hasil uji chi-square, hubungan antara pemasangan kawat kasa nyamuk pada ventilasi rumah dengan kejadian malaria didapat nilai $\mathrm{p}=0,004$, dengan demikian $p$ value lebih kecil dari alpha (5\%) sehingga Ha diterima, maka secara statistik dapat dikatakan ada hubungan yang bermakna antara pemasangan kawat kasa nyamuk dengan kejadian malaria di wilayah Kecamatan Toho. Hasil perhitungan Odds Ratio(OR) diperoleh nilai 6,875 dengan $95 \%$ confidence Interval $(\mathrm{CI})=1,835-$ 25,751, maka responden yang tidak memasang kawat kasa nyamuk mempunyai risiko 6,875 kali tertular penyakit malaria dibanding dengan responden yang tidak memasang kawat kasa.

Tabel 2 menunjukkan kecenderungan responden pada kasus yang memiliki hewan ternak sebanyak yaitu sebesar $63,8 \%$

Hasil uji chi-square, hubungan antara keberadaan hewan ternak dengan kejadian malaria didapat nilai $\mathrm{p}=0,004$, dengan demikian $p$ value kurang dari alpha (5\%) sehingga Ha diterima, maka secara statistik dapat dikatakan ada hubungan yang bermakna antara keberadaan hewan ternak dengan kejadian malaria di wilayah Puskesmas Toho. Hasil perhitungan Odds Ratio (OR) diperoleh nilai 3,765 dengan $95 \%$ confidence Interval $(\mathrm{CI})=1,602-$ 8,848; maka responden yang memiliki hewan ternak mempunyai risiko 3,765 kali tertular penyakit malaria dibanding responden yang tidak memiliki hewan ternak.

Tabel 2 menunjukkan responden yang terdapat genangan air di sekitar rumah pada kasus lebih tinggi dari kontrol yaitu sebesar $87,2 \%$.

Hasil uji chi-square, hubungan antara Genangan Air disekitar Rumah dengan kejadian malaria didapat nilai $\mathrm{p}=0,005$, dengan demikian $p$ value lebih kecil dari alpha (5\%), sehingga Ha diterima maka secara statistik dapat dikatakan ada hubungan yang bermakna antara genangan air disekitar rumah dengan kejadian malaria di wilayah Kecamatan Toho. Hasil perhitungan Odds Ratio (OR) diperoleh nilai 4,241 dengan 95\% Confidence Interval $(C I)=1,500-11,989 ;$ maka responden yang terdapat genangan air disekitar rumah 4,241 kali tertular penyakit malaria dibanding dengan responden yang tidak terdapat genangan air disekitar rumah responden. 


\section{Pembahasan}

Berdasarkan hasil penelitian terdapat hubungan antara kebiasaan keluar rumah pada malam hari dengan kejadian malaria didapatkan Orang yang memiliki kebiasaan keluar rumah pada malam hari memiliki risiko 2,843 kali terular penyakit malaria dibandingkan dengan orang yang tidak keluar rumah pada malam hari

Kebiasaan responden yang sering keluar rumah pada malam hari, memberi peluang nyamuk Anopheles untuk menggigit. Hal ini sesuai dengan hasil penelitian Matthys et al(2006), mengamati kebiasaan keluar malam penduduk pada daerah persawahan di Côte D'ivoire kota kecil di Afrika, menunjukkan bahwa risiko pada mereka yang sering berada di luar rumah pada malam hari mempunyai risiko cukup tinggi untuk malaria dengan $\mathrm{OR}=3,97$

Hasil penelitian Babba dkk (2006) di Kota Jayapura menemukan bahwa kebiasaan keluar rumah pada malam hari berpengaruh signifikans terhadap kejadian malaria dengan nilai OR: 5,54. Hal ini dapat disimpulkan bahwa kebiasaan keluar rumah pada malam hari berpeluang terkena malaria 5,54 kali dibandingkan orang yang tidak keluar rumah padamalam hari.

Mengingat hal tersebut, perlu adanya upaya dalam pencegahan dan pemberantasan penyakit malaria yang ditujukan pada kebiasaan keluar rumah pada malam hari, karena berdasarkan hasil penelitian yang diperoleh yaitu sebesar $51,1 \%$ responden yang mempunyai kebiasaan keluar rumah pada malam hari, maka diharapkan kepada masyarakat; diusahakan tidak keluar rumah pada malam hari, kalaupun harus keluar, sebaiknya menggunakan pelindung diri, baik berupa pakaian panjang maupun menggunakan obat anti nyamuk oles atau repellent.

Hubungan pemakaian kelambu dengan kejadian malaria berdasarkan ui statistik sesuai dengan tabel 2 dan secara statistik dapat dikatakan ada hubungan yang bermakna antara penggunaan kelambu dengan kejadian malaria di wilayah Kecamatan Toho. Orang yang tidak menggunakan kelambu saat tidur malam hari memiliki risiko 3,419 kali tertular penyakit malaria dibanding dengan orang yang menggunakan kelambu saat tidur malam hari (OR : 3,419; $95 \%$ CI 1,465$7,978)$.

Penggunaan kelambu merupakan upaya efektif untuk mencegah dan melindungi dari gigitan nyamuk saat tidur malam hari.

Hasil penelitian menunjukan bahwa pemakaian kelambu sangat signifikan dengan kejadian malaria di wilayah Kecamatan Toho.Orang yang tidak pernah menggunakan kelambu 3,419 kali lebih besar untuk menderita malaria.Artinya, pemakaian kelambu sangat efektif dalam mencegah penularan malaria. 
Memakai kelambu merupakan salah satu cara untuk menghindari gigitan nyamuk baik dengan kelambu berinsektisida maupun tidak. Hasil penelitian Erdinal dkk(2006) terhadap pemakaian kelambu, menemukan bahwa penduduk yang tidak memakai kelambu waktu tidur pada malam hari mempunyai risiko 2,4 kali dengannilai $\mathrm{p}=$ 0,017 dan OR 2,4 dengan CI (1,226-4,845). Sedangkan penelitian yang dilakukan Munawar(2005) di Kabupaten Banjarnegara Jawa Tengah menemukan bahwa terdapat hubungan yang signifikan antara penggunaan kelambu terhadap kejadian malaria (OR : 8,09, 95 \% CI : 1,99 -32,9).

Mengingat bahwa penggunaan kelambu sangat sefektif dalam pencegahan penyakit malaria, diharapkan kepada instansi terkait seperti puskesmaspuskesmas yang ada di Kecamatan Toho, agar mempromosikan penggunaan kelambu kepada masyarakat, sehingga dapat menurunkan angka kejadian malaria. Berdasarkan data yang diperoleh bahwa proporsi responden yang tidak menggunakan kelambu saat tidur malam yaitu sebesar 48,9\%, maka diharapkan kepada masyarakat, khususnya di wilayah Kecamatan Toho untuk menggunakan kelambu terutama waktu tidur malam hari sehingga terhidar dari kontak terhadap nyamuk Anopheles.

Ada hubungan penggunaan obat anti nyamuk dengan kejadian malaria dengan nilai $p$ value: 1,000 hal ini sesuai dengan tabel 2 maka secara statistik dapat dikatakan tidak ada hubungan yang bermakna antara penggunaan obat anti nyamuk dengan kejadian malaria dengan nilai OR sebesar $0,885(95 \% \mathrm{CI}=0,335-2,337)$

Tidak adanya hubungan antara penggunaan obat anti nyamuk dengan kejadian malaria, ini dikarenakan obat anti nyamuk yang digunakan yaitu obat anti nyamuk bakar, sedangkan kondisi fisik rumah responden masih banyak ditemukan dinding yang tidak kedap nyamuk, sehingga kurang efektif untuk mengusir nyamuk. Selain itu prilaku penduduk yang lebih dominan hanya menggunakan obat anti nyamuk pada saat akan tidur saja serta adanya kebiasaan masyarakat yang sering keluar rumah pada malam hari dan dudukduduk di beranda rumah sehingga upaya perlindungan dari gigitan nyamuk melalui penggunaan obat anti nyamuk menjadi tidak maksimal.

Meskipun tidak ada hubungan bermakna antara penggunaan obat anti nyamuk dengan kejadian malaria, tetapi setidaknya penggunaan obat anti nyamuk dapat mengurangi gigitan nyamuk kepada seseorang.

Hasil penelitian Erdinal dkk (2006) terhadap pemakaian obat anti nyamuk, menemukan bahwa penduduk yang memakai obat anti nyamuk waktu tidur pada malam hari mempunyai risiko 2,3 kali untuk 
terjadinya malaria dibandingkan dengan yang tidak memakai obat anti nyamuk waktu tidur pada malam hari, dengan nilai $\mathrm{p}$ $=0,026$ dan OR 2,3 dengan CI (1,1584,564). Penelitian yang dilakukan Munawar (2005) menemukan hubungan yang signifikan antara pemakaian reppelant terhadap kejadian malaria (OR : 9,53, $95 \%$ CI : 4,33 - 62,23).

Menurut Munif (2009) salah satu pencegahan untuk terjadinya kontak dengan nyamuk Anopheles dengan menggunakan obat anti nyamuk seperti repellent karena bahan yang terkandung dalam repellent mampu menghindari kontak dengan nyamuk.

Ada hubungan kondisi dinding rumah dengan kejadian malaria dengan nilai $p$ value : 0,000 dengan nilai $\mathrm{OR}=6,982(95 \%$ CI : 2,804 - 17,382) maka dapat dikatakan ada hubungan bermakna antara kondisi diding rumah dengan kejadian malaria, hal ini sesuai dengan tabel 2, responden yang kondisi diding rumahnya yang berisiko mempunyai risiko 6,982 kali tertular penyakit malaria dibanding dengan responden yang dinding rumahnya tidak berisiko.

Adanya hubungan antara kondisi dinding rumah dengan kejadian malaria, karena dengan adanya celah-celah pada dinding rumah, ini memberi kesempatan nyamuk anopheles dengan leluasa masuk kedalam rumah dan menggigit penghuni rumah dan akan menyebabkan terjangkit penyakit malaria.

Kondisi dinding rumah cukup signifikan pengaruhnya terhadap kejadian malaria. Hasil penelitian juga menunjukan bahwa kondisi diding rumah merupakan faktor yang dominan dalam menyebabkan malaria di wilayah Kecamatan Toho, terlihat dari hasil persentasenya yaitu sebanyak $54,3 \%$.

Hasil penelitian Babba dkk (2006) di Kota Jayapura menunjukkan bahwa dinding rumah yang dari kayu/papan merupakan faktor risiko terjadinya malaria $(\mathrm{p}=0,004)$ dengan nilai OR : 3,14 (95\% CI : 1,436,88). Dengan demikian orang yang memiliki dinding rumah dari kayu/papan mempunyai risiko 3,14 kali untuk terkena malaria dibandingkan orang yang memiliki dinding rumah dari tembok.

Diharapkan, terutama masyarakat wilayah Kecamatan Toho agar lebih memperhatikan kondisi dinding rumahnya, sebaiknya jangan ada celah-celah yang memberi kesempatan nyamuk Anopheles bisa dengan leluasa masuk kedalam rumah.

Ada hubungan pemakaian kawat kasa nyamuk pada ventilasi dengan kejadian malaria dengan nilai $p$ value : 0,002 dengan nilai $\mathrm{OR}=6,875(95 \% \mathrm{CI}: 1,835-25,751)$ maka secara statistik dapat dikatakan ada hubungan bermakna antara pemakaian kawat kasa nyamuk dengan kejadian malari, hal ini sesuai dengan tabel 2. 
Berdasarkan penelitian dilapangan adanya hubungan bermakna antara pemasangan kawat kasa nyamuk dengan kejadian malaria yaitu sebesar 80,9\%. walaupun kawat kasa terpasang pada ventilasi, namun keadaan kawat tersebut rusak/bolong, sehingga nyamuk bisa dengan leluasa masuk ke dalam rumah. Sedangkan fungsi pemasangan kawat kasa nyamuk yaitu sebagai penghalang sehingga jumlah nyamuk yang masuk kerumah dapat diminimalisir.

Pemasangan kawat kasa pada ventilasi rumah merupakan salah satu cara untuk mencegah nyamuk masuk ke rumah dan menggigit penghuninya. Hasil penelitian Erdinal dkk(2006) menemukan bahwa masyarakat yang tidak memasangkawat kasa di ventilasi rumahnya mempunyai risiko 2,3 kali, dengan nilai $\mathrm{p}=$ 0,027 dan OR 2,3 dengan CI (1,153-4,513). Hal ini menunjukkan bahwa pencegahan gigitan nyamuk dengan menggunakan kawat kasa di setiap rumah merupakan langkah pencegahan terhadap kontak dengan nyamuk. Hal yang sama juga di buktikan dari hasil penelitian Babba dkk (2006) di Kota Jayapura yang menunjukkan bahwa kawat kasa yang tidak terpasang pada semua ventilasi merupakan faktor risiko terjadinya malaria, rumah yang tidak memasang kawat kasa pada ventilasi berisiko terkena malaria 2,14 kali daripada orang yang rumahnya memasang kawat kasa pada semua ventilasi (OR : 2,$14 ; 95 \%$ CI : 1,02 - 4,47).

Ada hubungan keberadaan hewan ternak dengan kejadian malaria dengan $p$ value : 0,002 dengan nilai $\mathrm{OR}=3,765$ (95\%CI : 1,602-8,848) maka dapat dikatakan ada hubungan bermakna antara keberadaan Hewan ternak dengan kejadian malaria, responden yang memiliki hewan ternak mempunyai risiko 3,765 kali tertular penyakit malaria dibanding dengan responden yang tidak memiliki hewan ternak.

Adanya hewan ternak disekitar rumah, ini sangat memberi peluang nyamuk Anopheles untuk berlindung. Karena hewan ternak merupakan tempat peristirahatan vektor nyamuk malaria, karena sifatnya terlindung dari cahaya matahari dan lembab. Sehingga keberadaan hewan ternak menjadi penting untuk diperhatikan karna bisa menjadi faktor risiko terjadinya kasus malaria.

Wilayah Kecamatan Toho pada umumnya penduduk menempatkan kandang ternak bersebelahan dengan rumah dan bahkan ada yang di kolong rumah, hal ini sebagai salah satu faktor dimana nyamuk dapat dengan mudah masuk kedalam rumah. Sehingga hubungan keberadaan hewan ternak dengan kejadian malaria sangat bermakna.

Hasil penelitian yang dilakukan oleh Erdinal dkk(2006) di Kabupaten Kampar 
menemukan bahwa pemelaharaan ternak besar di sekitar tempat tinggal mempunyai hubungan yang signifikan terhadap terjadinya malaria dengan nialai OR sebesar 3,2 (95 CI 1,650-6,693). Penelitian Babba dkk(2006) di Kota Jayapura juga menemukan bahwa keberadaan ternak besar disekitar rumah merupakan faktor risiko terjadinya malaria $(\mathrm{p}=0,01)$ dengan nilai $\mathrm{OR}$ : 2,44 (95\% CI : 2,21-4,90).

Menurut Saepudin(2003)keberadaan kandang ternak sapi/kerbau dapat mencegah kontak dengan manusia (Cattle barrier) jika perletakannya tepat. Kandang ternak merupakan tempat peristirahatan vektor nyamuk malaria sebelum dan sesudah kontak dengan manusia, karena sifatnya terlindung dari cahaya matahari dan lembab. Selain itu beberapa jenis nyamuk Anopheles ada yang bersifat zoofilik dan antropofilik atau menyukai darah binatang dan darah manusia (Inge, 2008). Sehingga keberadaan hewan ternak menjadi penting untuk diperhatikan karna indikasi faktor risiko untuk terjadinya kasus malaria.

Mengingat hal tersebut, perlu ada upaya pencegahan dan pemberantasan penyakit malaria yaitu berupa; menjaga kebersihan kandang ternak, jika kandang ternak baru akan dibuat, sebaiknya kandang ternak dibuat jauhdari rumah.

Ada hubungan adanya genangan air di sekitar rumah dengan kejadian malariadengan nilai $p$ value : 0,004 dengan nilai $\mathrm{OR}=4,241 \quad(95 \% \mathrm{CI}: 1,500-11,989)$ maka dapat dikatakan ada hubungan bermakna antara genangan air disekitar rumah dengan kejadian malaria, hal ini sesuai dengan tabel 2 responden yang terdapat genangan air disekitar rumah mempunyai risiko 4,241 kali tertular penyakit malaria dibanding dengan responden yang tidak terdapat genangan air disekitar rumah.

Adanya genangan air disekitar rumah, ini memberi kesempatan nyamuk untuk berkembang biak, sehingga jumlah populasi nyamuk disekitar rumah bertambah dan frekuensi tergigit nyamuk menjadi lebih besar.

Hasil penelitian menunjukkan terdapat genangan air disekitar rumah yaitu sebesar 74,5\% mengingat bahwa keberadaan tempat perindukan nyamuk seperti genangan air disekitar rumah memiliki risiko yang lebih besar untuk terjangkit malaria, maka diharapkan kepada masyarakat di wilayah Kecamatan Toho, terutama lingkungan rumah yang terdapat genangan air agar menghilangkan atau mengurangi dengan memodifikasi lingkungan yaitu pengeringan pada lahan yang tergenang air, kemudian lakukan penimbunan dengan tanah atau pasir. Jika keadaan tidak memungkinkan dapat dilakukan dengan penebaran ikan pemakan larva nyamuk yaitu suatu upaya memanfaatan ikan sebagai musuh alami 
larva nyamuk yang ditebarkan pada tempat perindukan potensial nyamuk dengan tujuan pengendalian populasi larva nyamuk, sehingga dapat mengurangi kejadian malaria. Jenis ikan yang ditebarkan seperti ikan kepala timah (Apolocheilus panchax) atau ikan nila merah.

Genangan air di sekitar rumah dapat berpotensi sebagai tempat perkembangbiakan nyamuk termasuk nyamuk vektor malaria. Sehingga orang yang rumahnya dekat dengan genangan air berisiko lebih tinggi menderita malaria.

Adanya tempat-tempat perindukan nyamuk anopheles sangat menentukan kepadatan nyamuk. Berdasarkan ukuran, lamanya air dan macam tempat air, maka genangan air dapat diklasifikasikan menjadi dua bagian, yaitu tempat genangan air yang besar dan tempat genangan air yang kecil. An. barbirostis menyukai tempat perindukan yang airnya statis atau mengalir sedikit, An. minimus menyukai tempat perindukan yang airnya cukup deras dan $A n$. letifer menyukai di tempat yang airnya tergenang (Sucipto,2011).

Berdasarkan data hasil penelitian, diharapkan kepada institusi yang terkait antara lain: Dinas Lingkungan Hidup diharapkan memodifikasi lingkungan dengan cara menutup tempat perindukan nyamuk dengan tanah atau pasir, atau penebaran ikan pemakan jentik pada lokasi tempat perindukan nyamuk yang potensial.
Kepada Dinas Pertanian agar berupaya memanipulasi lingkungan dengan cara pengaturan perairan persawahan, dan kepada masyarakat diharapkan agar mengatur pembuangan limbah serta selalu menjaga kebersihan disekitar rumah.

\section{Simpulan}

(1)Ada hubungan bermakna antara kebiasaan keluar malam dengan kejadiaan malaria di wilayah Kecamatan Toho. (2) Ada hubungan bermakna antara penggunaan kelambu dengan kejadian malaria di wilayah Kecamatan Toho. (3) Tidak ada hubungan bermakna antara penggunaan obat anti nyamuk dengan kejadian malaria di wilayah Kecamatan Toho.(4) Ada hubungan bermakna antara kondisi diding rumah dengan kejadian malaria di wilayah Kecamatan Toho . (5) Ada hubungan bermakna antara pemakaian kawat kasa pada ventilasi dengan kejadian malaria di wilayah Kecamatan Toho. (6) Ada hubungan bermakna antara keberadaan hewan ternak dengan kejadian malaria di wilayah Kecamatan Toho. ( 7) Ada hubungan bermakna antara keberadaan genangan air disekitar rumah dengan kejadian malaria di wilayah Kecamatan Toho. 


\section{Daftar Pustaka}

Babba. 2006. Faktor-faktor Risiko yang Mempengaruhi Kejadian Malaria (Studi Kasus di Wilayah Kerja Puskesmas Hamadi Kota Jayapura)

Depkes RI, 2009, Pedoman Surveilans Malaria, Ditjen PP \& PL Depkes, Jakarta.

Dinkes Provinsi Kalimantan Barat, 2010.

Data P2-PL Malaria. Dinas

Kesehatan Provinsi Kalimantan Barat,

Pontianak.

Erdinal, dkk, 2006, Faktor-faktor yang Berhubungan dengan Kejadian Malaria diKampar Kiri Tengah Kabupaten Kampar, Makara

Kesehatan Vol 10 No.2 Bulan

Desember 2006 : 64-70

Inge, Sutanto. 2008. Buku Ajar Parasitologi

Kedokteran.Balai Penerbit.

Munif dan Imron. 2009. Panduan

Pengamatan Nyamuk dan Vektor

Malaria. Sagung Seto. Jakarta.

Murti, B. 1997. Prinsip dan Metode Risep Epidemiologi, Gadjah Mada University Press, Yogyakarta.
Matthys et al. 2006. Panduan Studi Epidemiologi \& Biostatistika, Penerbit Buku Kedokteran EGC, Jakarta.

Munawar, 2005, Faktor Risiko Kejadian Malaria di Desa Segeblog Wilayah Puskesmas Banjarmangu I Kabupaten Banjarnegara JawaTengah. Tesis. Program Pasca Sarjana Universitas Diponegoro, Semarang

Saepudin, Malik, 2003. Prinsip-prinsip Epidemiologi. STAIN Pontianak Press, Pontianak.

Sucipto, Cecep Dani, 2011, Vektor Penyakit Tropis, Gossyen Publishing, Yogyakarta

Sucipto, Cecep Dani,Bionomik Vektor Malaria Di Entikong Kalbar, Jurnal Ilmiah Kesehatan, Poltekes Kesehatan Pontinak 